\section{A proposal for grading nasomucosal injury as a complication of transnasal endoscopy}

Unsedated transnasal esophagogastroduodenoscopy (EGD) using an ultrathin scope has been developed as an alternative method to conventional endoscopy with sedation $[1,2]$. Several studies have reported the benefit of transnasal EGD, which may reduce the risk of cardiopulmonary complications, lower the cost related to postprocedure monitoring, and be better tolerated by the patients $[1-3]$. However, lack of data regarding the safety of the procedure hinders widespread usage of unsedated nasal endoscopy [4]. In fact, according to the Technology Status Evaluation Report of the American Society for Gastrointestinal Endoscopy, the complication rate associated with nasal EGD remains unknown [5]. Thus, it may be useful to determine criteria for estimating the complications related to nasal EGD, including epistaxis, which occurs in a few percent of patients. We propose a grading system for nasomucosal injury caused by the transnasal insertion of an endoscope.

We performed unsedated transnasal EGD in 1665 consecutive patients at Inuyama Chuo Hospital between June 2004 and April 2007, employing an ultrathin endo-

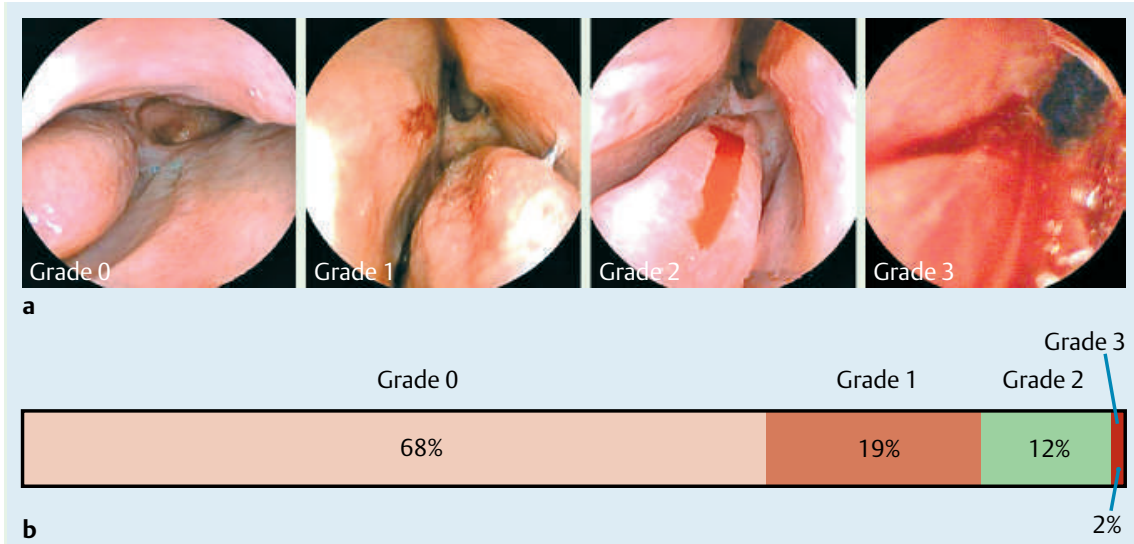

Fig. 1 Grades of nasomucosal injury. a Endoscopic view of the nasal mucosa in each grade. Grade 0 , normal mucosa; grade 1, mucosal redness; grade 2, oozing hemorrhage; grade 3, overt bleeding. b Percentage of patients in each grade.

scope (EG530N5; Fujinon-Toshiba, Tokyo, Japan). We were unable to complete nasal endoscopy in 96 cases $(5.8 \%)$ due to failure of insertion. Thus, a total of 1569 patients were enrolled in the present analysis (841 male and 728 female; median age 59 years, range $16-90$ years). At termination of the endoscopy, nasomucosal injury was assessed using the following grading system: grade 0 , normal mucosa; grade 1 , mucosal redness; grade 2 , oozing hemorrhage; grade 3 , overt bleeding ( $\bullet$ Fig. 1 a). The percentage of patients in each grade is shown in Fig. $\mathbf{1} \mathbf{b}$. The hemorrhage was self-limiting and no patient required nasopharyngeal treatment. To our knowledge, this is the first proposal for grading nasomucosal injury caused by transnasal EGD. We believe that grading is useful for diagnosis of endoscopy-related nasomucosal complications and for further evaluation of the safety of nasal endoscopy.

Endoscopy_UCTN_Code_CPL_1AH_2AB Endoscopy_UCTN_Code_CPL_1AH_2AK

$$
\text { a }
$$

b Percentage of patients in each grade.

\section{A. Mori ${ }^{1}$, N. Ohashi ${ }^{1}$, T. Maruyama ${ }^{1}$, M. Ito' ${ }^{2}$, T. Miyawaki ${ }^{3}$, M. Okuno ${ }^{1}$}

${ }^{1}$ Department of Gastroenterology, Inuyama Chuo Hospital, Aichi, Japan

2 Ito Clinic, Nihonbashi Chuo-ku, Osaka, Japan

3 Izumo Central Clinic, Enya-cho, Izumo, Japan

\section{References}

1 Saeian K. Unsedated transnasal endoscopy: a safe and less costly alternative. Curr Gastroenterol Rep 2002; 4: 213-217

2 Dumortier J, Napoleon B, Hedelius F et al. Unsedated transnasal EGD in daily practice: results with 1100 consecutive patients. Gastrointest Endosc 2003; 57: 198 - 204

3 Mori A, Fushimi N, Asano T et al. Cardiovascular tolerance in unsedated upper gastrointestinal endoscopy: prospective randomized comparison between transnasal and conventional oral procedures. Dig Endosc 2006; 18: $282-287$

4 Botoman VA. Ultrathin crossroads: is smaller better? Gastrointest Endosc 2003; 57: 377-380

5 Nelson DB, Block KP, Bosco JJ et al. ASGE Technology Status Evaluation Report. Ultrathin endoscopes esophagogastroduodenoscopy. Gastrointest Endosc 2000; 51: $786-$ 789

\section{Bibliography}

DOI 10.1055/s-2007-995491

Endoscopy 2008; 40: E60 -E60

(c) Georg Thieme Verlag KG Stuttgart · New York . ISSN 0013-726X

\section{Corresponding author}

\section{A. Mori, MD}

Department of Gastroenterology Inuyama Chuo Hospital Aichi 484-8511

Japan

Fax: +81-568-62-8761

a-mori@inuyamachuohospital.or.jp 